ISSN 1981-416X

Licenciado sob uma Licença Creative Commons

\title{
Metodologia de narrativas autobiográficas na formação de educadores
}

\author{
Methodology of autobiographical narratives \\ in teacher training
}

\author{
Lidnei Ventura ${ }^{[a]}$, Dulce Márcia Cruz ${ }^{[\mathrm{b}]^{*}}$ \\ [a] Universidade do Estado de Santa Catarina, Florianópolis, SC, Brasil \\ [b] Universidade Federal de Santa Catarina (UFSC), Florianópolis, SC, Brasil
}

\section{Resumo}

A experiência de pesquisa ora relatada inscreve-se numa investigação mais ampla de doutorado em andamento, que estuda narrativas autobiográficas de um grupo de alunas egressas do curso de Pedagogia a distância do Centro de Educação a Distância (CEAD), da Universidade do Estado de Santa Catarina. O foco do presente artigo é o potencial formativo da metodologia de narrativas autobiográficas (memoriais) coletadas no espaço biográfico do curso de extensão intitulado "Narrativa, autobiografia e formação de educadores", destinado à formação continuada de egressos, promovido pelo CEAD. Memoriais autobiográficos, narrados em primeira pessoa, oferecem ao pesquisador farto material de investigação acerca das possibilidades (auto)formativas do relato de experiências na formação inicial e continuada de educadores. Neste trabalho, parte-se do princípio benjaminiano 
de que narrativas, além de se constituírem como (re)produções e transmissões de histórias, são essencialmente partilhas de experiências de vida. O movimento de pesquisa e formação oferecido no referido curso priorizou três momentos (auto)formativos interdependentes: o exercício da experiência narrativa, a socialização da experiência narrativa e a (meta)reflexão sobre a experiência narrativa. Além de descrever o funcionamento do curso, o presente artigo apresenta os fundamentos da metodologia de formação continuada com narrativas e os resultados da pesquisa com memoriais autobiográficos. Como resultados prévios, constatou-se a importância da pesquisa narrativa no âmbito das ciências humanas, bem como suas possibilidades inovadoras de construção de conhecimentos, habilidades e competências acadêmicas e profissionais por parte dos sujeitos educadores pesquisados em formação.

Palavras-chave: Narrativa. Formação continuada. Metodologia de narrativa autobiográfica. Educação a distância.

\section{Abstract}

The research experience reported here is part of doctoral research in progress, which studies autobiographical narratives of a group of graduate students at the Pedagogy Course of the Center of Distance Learning (CEAD), of State University of Santa Catarina. The focus of this article is the formative potential of the methodology of autobiographical narratives (memorials) collected in the biographical space of the extension course called "Narrative, autobiography and training of educators", destined to the continuing education of graduates, promoted by CEAD. Autobiographical memorials, narrated in the first person, offer the researcher a wealth of research material about the (self) formative possibilities of reporting experiences in the initial and ongoing formation of educators. This work is based on Benjamin's principle that narratives, besides being constituted as (re)productions and transmissions of stories, are essentially a sharing's of life experiences. The research and training movement offered in this course prioritized three interdependent (self) formative moments: the exercise of narrative experience, the socialization of narrative experience and (meta) reflection on the narrative experience. In addition to describing the functioning of the course, this article presents the fundamentals of the methodology of continuing 
education with narratives and the results of the research with autobiographical memorials. As previous results, it was verified the importance of narrative research in the scope of the human sciences, as well as their innovative possibilities of construction of knowledge, skills and academic and professional competences on the part of the studied educator subjects in training.

Keywords: Narrative. Continuing education. Methodology of autobiographical narrative. Distance education.

\section{Introdução}

Pode-se dizer que o interpretador é parte do enunciado a ser interpretado Bakhtin (Estética da criação verbal)

Nas últimas três décadas a pesquisa com narrativas tem alçado patamares cada vez mais altos no âmbito das ciências humanas (HARRISON, 2008; ANDREWS; SQUIRE; TAMBOUKOU, 2008). Percebe-se, neste período, a emergência de um fenômeno que tem sido chamado de "redescoberta do sujeito", no bojo de outro que tem marcado sobremaneira as humanidades: os vários turnos de "virada linguística". Ambos fenômenos estão ancorados na constituição do gesto fundamental da hermenêutica fenomenológica moderna que, desde Schleiermacher, tem legado ao sujeito leitor a responsabilidade de atribuição de sentidos aos mais diferentes textos narrativos, atitude antes intrínseca à própria literalidade do texto. Desde Schleiermacher, "[...] o ato da compreensão é a realização reconstrutiva de uma produção" (GADAMER, 2014, p. 263); ou seja, cabe agora ao sujeito a reconstrução da autoria de determinada narrativa no seu esforço de compreensão e superação da distância que o separa do texto e do autor original. Neste 
passo, pode-se afirmar, como na epígrafe de Bakhtin, que o intérprete é parte integrante da arte da compreensão.

Ainda que tardiamente, o cenário atual é de valorização dos relatos pessoais, biográficos e autobiográficos, de modo que pesquisas narrativas vêm alcançando patamares cada vez mais importantes no cenário das investigações em ciências humanas, ganhando espaço como metodologia de pesquisa, forma de exposição e em processos de formação, principalmente de educadores.

As pesquisas, em ciências humanas, em suas diferentes áreas, têm discutido o papel e a importância das narrativas autobiográficas no processo de individuação e construção de identidades, partindo de pressupostos e métodos antropológicos e etnográficos, áreas que reafirmam o papel do sujeito e de sua subjetividade no centro da pesquisa científica (JOSSO, 2010; ABRAHÃO, 2004).

Motivados e impulsionados no Brasil pela virada linguística da década de 1960, principalmente pelos estudos história oral, pesquisadores brasileiros têm enfrentado rupturas epistemológicas no campo historiográfico, apontando para as possiblidades metodológicas de outras fontes e formas de produção/socialização de conhecimentos. Neste âmbito, colocam em questão as narrativas "objetivas" de fontes escritas (FERREIRA, 2002), ao tempo em que advogam uma postura "ativista" e de comprometimento com exercícios de história oral e com narratividades não presentes nos documentos oficiais; desta forma, propõem-se a ouvir vozes excluídas e promover testemunhos de situações de sofrimentos extremos (MEIHY, 2006). Tal impulso, que atualmente ganha contornos interdisciplinares, traz para o campo acadêmico, sobretudo para a área educacional, a riqueza narrativa de vozes até então desprestigiadas na produção de saberes e restritas ao universo universitário. De modo que se avolumam pesquisas e pesquisadores brasileiros e latino-americanos que voltam seus olhares para a pesquisa narrativa com professores (ABRAHÃO, 2004), comunidade escolar (DANTAS, 2014), alunos da educação de jovens e adultos (ANDRADE, 2008), alunos de graduação e pós-graduação (SOUZA, 2008), (auto) 
biografias migratórias (ARFUCH, 2013) e diversos outros sujeitos produtores de narrativas-saberes-conhecimentos do multifacetado campo sócio-educacional.

Entretanto, ao contrário do que pode parecer à primeira vista, não há consenso do que seja de fato uma narrativa e seus sentidos são múltiplos, tratando-se de um território contestado cujo significado está "em disputa" (ANDREWS, SQUIRE, TAMBOUKOU, 2013). Em vista disso, a primeira tarefa a que se propõe este trabalho é justamente apresentar um significado provisório, entre tantos, de narrativa, concebendo-a como partilha de experiências (BENJAMIN, 2012). Definido o conceito, posteriormente argumenta-se sobre suas possibilidades de conversão em metodologia de pesquisa e formação, a partir da descrição de um processo de investigação envolvendo narrativas (auto)biográficas.

\section{Narrativas como partilha de experiências}

Narrativas nos constituem como pessoas, como sujeitos, como identidades subjetivas. Mas não só. Narrativas nos constituem como espécie, como gênero humano, como mundo, como universo. E é a partir delas que damos significado ao mundo à nossa volta, seja considerando os aspectos filogenéticos ou ontogenéticos do gênero humano. A tese de Paul Ricoeur vai mais além, dizendo que é pela narrativa que damos sentido ao tempo, localizando nele a experiência humana. Diz o autor que “ [...] o tempo se torna tempo humano na medida em que está articulado de maneira narrativa; em contraposição, a narrativa é significativa na medida em que desenha as características da experiência temporal" (RICOEUR, 2010, p. 09).

Por mais que os homens inventem novos meios de expressão de sua experiência no mundo, o narrador e a narrativa, como disse Walter Benjamin, desenvolvem "uma forma artesanal de comunicação" (2012, p. 221) nunca acabada ou concluída, mas como um "puro em si", como "a mão do oleiro na argila do vaso". De forma que a narrativa mais antiga, sempre que recontada, cria todo um mundo novo, enfatizando 
personagens, decalcando cenas ou mesmo reinventando enredos. É esse estado permanente de (re)invenção da história que garante a atualidade sempre renovada da narrativa.

Como parte constitutiva do ser humano por excelência, o ato de narrar não pode ser concebido apenas como transmissão de histórias, verídicas ou não, mas deve ser tomado como partilha e intercâmbio de experiências (BENJAMIN, 2012), como encontro com o outro, que afeta e é afetado pelos relatos acerca de seu percurso identitário. Daí os arquétipos benjaminianos de autoridades narrativas serem o marujo e o velho camponês sedentário. Os marujos podem partilhar suas experiências (erfahrung) conquistadas em longas viagens pelo mundo; por seu turno, o velho camponês, por ter realizado a também longa viagem da vida e conhecido tão bem o seu lugar e suas tradições, também tem muito a contar. De qualquer forma, ambos narradores podem ensinar com suas histórias porque elas estão carregadas de experiências, das quais podem se extrair conselhos e sabedorias. Decorre justamente daí a mal compreendida e polêmica de uma suposta lamentação de Benjamin sobre a decadência da narrativa na modernidade. Parece, ao contrário, que sua reflexão não vai contra a narrativa atual, mas que ao realizá-la sejam socializadas não apenas vivências (erlebnis) superficiais, sem conteúdos vitais e fragmentários, mas verdadeiras partilhas de experiências, da qual se possa extrair uma norma de vida, um ensinamento moral, um provérbio ou uma sugestão prática. De qualquer forma, "o narrador é um homem que sabe dar conselhos. [...] O conselho tecido na substância da vida vivida tem um nome: sabedoria" (BENJAMIN, 2012, p. 216). Ao reclamar da enxurrada de notícias que invadem a vida moderna pelo choque de informações pulverizadas, Benjamin alerta para o fato de que "a arte de narrar aproxima-se do seu fim porque a sabedoria - o lado épico da verdade - está em extinção" (2012, p. 217). Ao que parece, o segredo de uma boa narrativa consiste em recuperar a autoridade de contar histórias que sejam assimiladas às experiências dos outros, porque têm algo a dizer. 
E um dos aspectos da pesquisa narrativa que mais pode impressionar é justamente sua tripla dimensão: fenômeno, método e exposição. É essa tridimensionalidade que discutiremos no próximo item.

\section{Narrativas como fenômeno, metodologia de pesquisa e de exposição de resultados}

É importante considerar que no processo investigativo, pesquisas narrativas e (auto)biográficas apresentam três dimensões que se impregnam mutuamente: são ao mesmo tempo o fenômeno a ser investigado, a metodologia de pesquisa adotada e a forma de exposição dos resultados da investigação.

Como diz a pesquisadora Moen Torril, investigação narrativa é "[...] o estudo de como os seres humanos experimentam o mundo, e pesquisadores narrativos coletam essas histórias e escrevem narrativas de experiência" (2008, p. 292). Ou seja, o fenômeno a ser investigado é a vida das pessoas, que se expressa na forma de narrativas de vida e (auto) biografias. E no afã de captar toda a complexidade possível do fenômeno narrativo, o sujeito pesquisador se põe a coletar dados, lançando mão dos recursos mais variados, a fim de capturar a multiplicidade comunicativa deste ser que se expressa e dialoga. Feito isso, constrói novas narrativas acerca das experiências que lhe foram transmitidas. E, é claro, as produções destas pesquisas estão no campo das metanarrativas, pois são escritas sobre o que lhes foi dito, sujeito ao lusco-fusco da memória, dos interesses e desejos dos seus informantes. Esse é um processo de intepretação que, conforme Bakhtin (2003, p. 408), só pode se dar na medida em que transformo "o alheio no 'meu alheio"” pela relação dialógica viva. Não pode se tratar de uma relação monológica, pois o objeto de estudo é o sujeito [expressivo e falante] e não uma coisa, "não pode tornar-se mudo; consequentemente, o conhecimento que se tem dele só pode ser dialógico" (BAKHTIN, 2003, p. 400, grifo do autor).

Por conta de tal complexidade, Torril conceitua assim a pesquisa narrativa: "Meu ponto de partida é que a abordagem narrativa é um 
quadro de referência, uma forma de refletir durante todo o processo de investigação, um método de pesquisa, e um método para representar o estudo [...] um postulado que alguns podem achar um pouco confuso e avassalador" (2008, p. 291). Por conta desta razões avassaladoras é que a pesquisa narrativa, embora esteja em alta, não é nada fácil de se realizar, sobretudo pelos riscos intrínsecos ao processo investigativo, que vão desde a adequação do método ao fenômeno, passando pelas complexas relações intersubjetivas entre pesquisadores e seus informantes, culminando com a produção de uma narrativa exequível sobre o pesquisado e sua aceitação no mundo acadêmico.

Segundo Andrews, Squire e Tamboukou, "a pesquisa narrativa, embora seja popular e envolvente, é difícil [...] Os dados narrativos podem facilmente parecer esmagadores: suscetíveis a intermináveis interpretações, por sua vez, triviais e profundamente significativos" (2008, p. 01). Muito diferente de uma perspectiva quantitativa, cujos dados podem ser classificados e estruturados de maneira estatística e seus resultados apresentados em gráficos e tabelas que praticamente falam por si, a pesquisa narrativa enfrenta uma série de problemas desde o começo.

Desde a definição do tema, a pesquisa narrativa desafia o pesquisador de alguma forma a objetivar o fenômeno, o que é muito difícil de ser feito se levarmos em conta que também o investigador está sob influência de uma série de pressupostos, preconceitos e contingências do campo que lhe desafiam.

Num campo movediço como esse cabe bem a indicação benjaminiana de método como desvio (umweg). Diz Benjamin (2016, p. 31): "Methode ist umweg. Darstellung als umweg" ["Método como desvio. Representação como desvio" (tradução nossa)]. Essa frase indica a concepção do método hermenêutico-interpretativo que adota e tem um duplo sentido de negação: por um lado, se opõe ao método como caminho reto [indutivo ou dedutivo] das ciências da natureza e consequente adequação às suas regras; e, por outro, a negação a um modo de exposição não desviante, claro, objetivo, seco e silogístico. 
E esse parece ser bem o caso de pesquisadores narrativos, ou seja, o de assumir a pesquisa narrativa como fenômeno, método e forma de exposição, admitindo que o que nos move são as subjetividades que envolvem esse campo e suas interações dialógicas, as histórias de vida, o relato dessas vidas, suas inquietações e suas intepretações sempre desviantes.

\section{Narrativas como metodologia de formação}

Ainda segundo Torril, “[...] não existem pessoas sem narrativas [...] a própria vida pode ser considerada uma narrativa no interior da qual encontramos uma série de outras histórias" (2006, p. 291). E a partir desse encontro de histórias, nos formamos enquanto sujeitos situados num determinado tempo-espaço num processo contínuo de (re)intepretação do mundo. Para Jorge Larrosa Bondía, "el ser humano es um ser que interpreta y, para esa autointerpretación, utiliza fundamentalmente formas narrativas" (2004, p. 12). Pode-se inferir destes autores que as narrativas são mesmo parte constituinte do que somos. Em poucas palavras: a condição de narrar é uma premissa ontológica, isto é, somos porque narramos e somos o que narramos.

Assim, os processos de autocompreensão de nós mesmos (identitários) devem passar, necessariamente, pela rede intercomunicativa de dizermos, para nós e para os outros (e vice-versa), quem éramos, quem somos e quem pensamos ser. Então, se toda identidade é produzida no diálogo consigo mesmo e com os outros, narrar é dividir experiências de vida, sabedorias, incompletudes, tramas individuais e coletivas, enfim, partilhar história "[...] más o menos nítida, más o menos delirante, más o menos fragmentada" (BONDIA, 2004, p. 16). Para o pesquisador narrativo, essas são sempre histórias significativas para a autodescoberta e consciência de si mesmo(a).

Neste contexto de discussão, passa-se a considerar a ideia de que exercícios de narrativas autobiográficas podem levar a processos de (auto)referenciamento e a diversos tipos de aprendizagens, tanto ao se 
considerar processos cognitivos rememorativos e memorialísticos, quanto a produção de diversos gêneros orais e escritos autobiográficos, por parte dos sujeitos aprendentes. Tal proposta remete à importância de se considerar perspectivas de formação inicial e continuada a partir de histórias de vida e relatos autobiográficos, de modo que se possa trabalhar e revolver, no processo de formação de educadores, dimensões esquecidas da subjetividade, tais como a imaginação, afetividade, sensibilidade, emoção e todas aquelas outras que foram banidas do processo formativo (JOSSO, 2010; PASSEGGI, 2011) em nome de uma inalcançável e ilusória objetividade do sujeito, construída pelo imaginário positivista.

O campo da educação brasileira tem sido marcado também por experiências de pesquisas que consideram as narrativas autobiográficas como processo teórico-metodológico na formação de educadores (ABRAHÃO, 2004). Essas pesquisas partem da reflexão pessoal e podem levar a tomadas de decisões conscientes a respeito de sua atuação pessoal e profissional. Nelas, parte-se do princípio de que narrativas autobiográficas podem conduzir a processos de (auto)referenciamento e consciência de si a partir da criação de um espaço de narrativa autobiográfica. Como diz Passeggi (2011, p. 154): “[...] as escritas autobiográficas mostram justamente à pessoa que narra essa descontinuidade, as rupturas, a imprevisibilidade, o fortuito e o papel das contingências como aspectos determinantes da experiência humana".

Apesar da sua boa aceitação no campo da pesquisa atualmente, as narrativas autobiográficas dos sujeitos-educadores não têm sido uma dimensão satisfatoriamente considerada nos processos de formação inicial ou continuada. Essa carência traz a necessidade da criação de um espaço autobiográfico que resgate a importante dimensão da vida pessoal e profissional, a fim de que sejam rememoradas (ou não) contribuições e lacunas, provocações e decepções do percurso formativo, levando a reflexões pessoais e coletivas junto aos seus pares com objetivo de "passar a limpo" (ARFUCH, 2010, p. 16) essa história e seguir adiante com mais "segurança". 
Assim, as narrativas autobiográficas ou narrativas de vida (JOSSO, 2010), além de serem potenciais repositórios de dados de pesquisa, podendo gerar produtos como relatos de experiência, dissertações, teses e artigos científicos, têm também a função de contribuir como metodologia de formação de educadores, partindo dos princípios de que "formar é sempre formar-se" (NÓVOA, 2010, p. 25) e de que produzir narrativas autobiográficas requer necessariamente inventariar o próprio processo formativo, levando a tomadas de consciência e atuação em tempos e espaços diversos.

Para que isso ocorra, é preciso proporcionar, pela formação, a emersão de identidades através da imersão em um espaço biográfico constituído de relatos e fragmentos autobiográficos. No entanto, é relevante considerar que esse mergulho individual pode se desdobrar, em algum momento, em relato de todos ou conclusões para o conjunto (ARFUCH, 2010), procurando se enfrentar as complexas relações de impregnação dialética entre a história individual e a história social que marcam a vida do sujeito-coletivo.

No item que se segue, descrevemos e apresentamos os resultados de uma pesquisa de formação de educadores a partir da metodologia da pesquisa narrativa autobiográfica.

\section{Pesquisando com narrativas autobiográficas}

A partir de agora, passamos a descrever a pesquisa com a metodologia de narrativas autobiográficas que foi realizada no interior do curso de formação "Narrativa, autobiografia e formação de educadores", oferecido pelo Centro de Educação a Distância (CEAD), da Universidade do Estado de Santa Catarina (UDESC). A proposição do curso se inscreve numa pesquisa mais ampla de doutorado, ${ }^{1}$ que estuda narrativas de um

\footnotetext{
${ }^{1}$ A referida pesquisa intitula-se "Transformação de identidade de egressos da EaD: travessias de identidade", que tem por base a pesquisa narrativa, iniciada em 2014, sob orientação da professora Dra Dulce Márcia Cruz, no Programa de Pós-graduação da Universidade Federal de Santa Catarina,
} 
grupo de egressas do curso de Pedagogia, na modalidade a distância, oferecido pelo CEAD da Universidade do Estado de Santa Catarina.

A versão piloto do curso, ofertada para 50 participantes, no primeiro semestre de 2016, foi realizada totalmente on-line, pelo ambiente virtual de ensino e aprendizagem (AVEA) do CEAD, em uma sala criada para essa oferta específica, exclusivamente para educadores egressos de cursos de Pedagogia, na modalidade a distância.

A coleta de dados foi realizada a partir de duas ferramentas usadas na plataforma Moodle durante o curso: 1. Fórum de Apresentação e Autorreferenciamento, no qual cada participante se apresentou; 2. Diário de bordo, cuja finalidade era a de que cada participante, ao final da formação, construísse o seu memorial autobiográfico de vida e de formação.

A pesquisa-formação teve como objetivo principal a inversão da lógica de formação, classicamente calcada na "concepção de formação escolar" (NÓVOA, 2010, p. 17) para a ênfase numa concepção de formação autoral e investigativa. Esse ponto de vista encontra ressonância em diversos pesquisadores (JOSSO, 2010; NÓVOA, FINGER, 1988) com proposta que o sujeito em formação saia do lugar comum de passividade e passe a atuar diretamente na própria formação, concebendo-a como autoformação (SOUZA, 2008).

Partiu-se do pressuposto de que ao rememorar o seu processo formativo e construir autobiografias e suas narrativas, os sujeitos mobilizam uma série de funções psicológicas superiores, produzindo saberes e socializando conhecimentos via de regra desconsiderados no tradicional processo de formação escolar.

Linha Educação e Comunicação. O curso de extensão apresentado é parte da coleta de dados e uma das fases da interação do pesquisador com as protagonistas da pesquisa, um grupo de alunas egressas do curso de Pedagogia a distância da UDESC. 


\section{A construção do espaço biográfico do curso "Narrativas e seus atores"}

Como já foi dito, o oferecimento do curso foi pensado na perspectiva de construir para e com os sujeitos em formação continuada, pedagogas egressas do curso de Pedagogia a distância, um espaço de construção autobiográfica e de autoformação. Assumindo esse ponto de vista, a arquitetura pedagógica do curso teve como parâmetro principal a criação de um espaço (auto)biográfico dialógico que permitisse aos sujeitos autoformadores elementos para construção do seu memorial. Para tanto, a estrutura do ambiente virtual de ensino e aprendizagem foi voltada para ações que permitissem a um só tempo interações polifônicas e a multiplicidade presente nos discursos individuais. A título de subsídio teórico, foi produzido especialmente para o curso um Livro Digital intitulado "Entremeando Narrativas", com dois capítulos, cujos conteúdos priorizaram dois elementos principais: 1 . Narrativa como partilha de experiência e construção de sentido do mundo; 2. Narrativa como metodologia de pesquisa e de formação. A partir dessa fundamentação teórica, os cursistas-narradores foram convidados a exercitar uma habilidade pouco usual nos processos de formação continuada: a metarreflexão da experiência de formação acadêmica.

Os dados coletados, apesar de parecerem avassaladores, como vimos, levaram em conta os momentos de: a) exercício da experiência; b) socialização da experiência vivida; c) metarreflexão da experiência.

Esses momentos serão utilizados também como categorias de análise da pesquisa-formação, cujos resultados passamos a apresentar.

a - O exercício da experiência

Bondía Larrosa diz que a "experiência é o que nos passa, o que nos acontece, o que nos toca. Não o que se passa, não o que acontece, ou o que toca" (2002, p. 21). Então, a experiência é algo que se exercita, se faz e na qual se é sujeito. Não se pode ter experiências pelos outros; podemos conhecê-las, mas não podemos vivenciá-las. De modo que, no curso, os sujeitos foram convocados a exercitar uma experiência que, para 
muitos, era inusitada: narrar o seu percurso formativo. A partir do fórum de apresentação e autorreferenciamento, deu-se o start para o exercício de extrair de cada sujeito as experiências escondidas nos labirintos da memória involuntária. Tal como ocorrido com Proust que, ao relembrar desejos e lembranças desencadeadoras de posturas e vontades adormecidas, na clássica reminiscência que o doce madeleine, mergulhado no chá lhe causa, é impulsionado a escrever sua grande obra Em busca do tempo perdido (1913-1927).

Deflagrado o processo, os sujeitos narradores passaram a organizar suas experiências de formação a partir do fio condutor, o memorial descritivo. Como todo memorial é construído a partir de lembranças e esquecimentos, a proposta foi de construção paulatina do diário a fim de que fosse vivido, em retrospecção, o processo formativo vivido no curso de Pedagogia a Distância e suas influências na (trans)formação de cada um e de todos. Desta forma, os narradores puderam construtivamente contar sua história de vida, compartilhar experiências e (re)significar seus processos formativos, pois, como afirma Abrahão, esse “[...] processo de construção tem na narrativa a qualidade de possibilitar a autocomprensão, o conhecimento de si, àquele que narra sua trajetória" (2004, p. 203).

$\mathrm{Na}$ medida em que a pesquisa-formação permitiu aos sujeitos o exercício da experiência narrativa, vieram à tona inúmeras vivências significativas. É isso que provocam os relatos autobiográficos de formação: a experiência de narrar experiências.

\section{$b$ - A socialização da experiência narrativa}

Walter Benjamin diz que o narrador tem um dom, e seu "dom é poder contar sua vida; sua dignidade é contá-la inteira", pois "o narrador figura entre os mestres e os sábios" (2012, p. 240). Desse modo, o espaço biográfico do curso, multivocal e polifônico, foi criado para que os sujeitos autoformadores primeiro se dessem conta da própria experiência que têm e, depois, que pudessem extrair dela processos memorialísticos e autobiográficos para transformá-los em percursos formativos. 
Nessa perspectiva, autobiografar-se significa extrair de si experiências e, a partir delas, produzir novos saberes e fazeres, da vida, da profissão, da formação. Do mesmo modo que socializar essas experiências significa partilhar não apenas conhecimentos formais e acadêmicos, mas conhecimentos de uma vida inteira. E, ainda que pesquisas narrativas possam ter diversas abordagens e diversos fundamentos, no fim das contas, "em última instância, seus objetivos são revelar vidas ou segmentos de vida das pessoas" (HARRISON, 2008, p. xxi).

Apenas alguns excertos dos fragmentos de vidas que coletamos no curso preencheriam muitas páginas e não caberiam no espaço deste artigo. No entanto, como exemplo dos resultados propícios da metodologia e também para fazer jus ao que foi narrado, deixaremos que algumas das contadoras tragam um pouco de suas histórias.

Como os memoriais socializam um extenso leque de experiências vividas por seus autores e, na medida em que se materializaram em documentos textuais, tornaram-se também produções autorais, que servem de materiais didáticos, pedagógicos e de pesquisa, ganhando uma dimensão totalmente nova para seus produtores e, especialmente, para seus leitores. Alguns deles surpreendem pelo encantamento com que falam da escola, da infância, ou da sua vida profissional adulta. Em todos, a escolha do magistério é motivo de alegria, o que, de alguma forma, entra em contradição com os discursos lamuriosos sobre a escola e sobre ser professor(a). Como no exemplo da fala de L., que festeja com orgulho a formatura no magistério: "Eu ali, ouvindo aquelas palavras, parecia que nem era comigo, parecia um sonho, ou melhor era um sonho sim, mais agora era um sonho realizado. Era eu... professora! ". E falando como se fosse um ajuste de contas consigo mesma, reflete: "Conforme eu havia prometido a mim mesma, que quando eu me formasse iria sair da empresa em que trabalhava, assim o fiz! E depois de três meses da minha formatura já estava trabalhando no primeiro Centro de Educação Infantil da minha vida".

Como nos excertos acima, há uma reiterada marca de emoções nas composições, trazendo para o campo da formação essa dimensão 
humana, tão importante e que não pode aflorar na formação tradicional porque ela é pensada "para" e não "com" os sujeitos-educadores. Neste mesmo sentido, as memórias, que ao serem despertadas podem alavancar potenciais esquecidos, são continuamente provocadas. Essa é uma função minimizada na formação clássica, pois é usada somente para retenção de conteúdos muitas vezes sem significados.

O relato de $\mathrm{M}$. também foca suas memórias no trabalho docente com os pequenos e o quanto lembrar disso traz boas recordações e reforça positivamente sua decisão pela profissão de professora. Assim relembra: "Nos idos dias do curso de Magistério [sic] eu me encontrava encantada com a possibilidade de estar dentro de uma sala só minha com crianças por todos os lados". E, olhando em retrospectiva, como se fora um inventário profissional, acrescenta, depois de orgulhosamente contar uma bela história de como seus alunos de cinco anos são autônomos: "Nossa Meu Deus [sic] simplesmente me dei conta que já não sou tão necessária para eles, pelo menos no quesito autonomia na rotina etc. Agora já estão se preparando para voar, mas sei que vão sempre querer voltar quando precisarem de mim, pois já conhecem bem o caminho...”.

Algo reiterado nas autorias é a dimensão do sonho, seja ele realizado ou projetado. Na citação acima de L., já vimos como o sonho perpassa a narrativa autobiográfica como a realização de um desejo. Corroborando esse aspecto, o relato de A., também formada no magistério de segundo grau, reitera a narrativa onírica que, enfim, tornou-se realidade: "Era a realização de um sonho [...] Mal podia esperar para conhecer a minha turma. Foi amor à primeira vista! Trinta crianças sentadas enfileiradas nas carteiras esperando para aprender. Pudera elas compreender que ali quem estava para aprender era eu".

Esses segmentos de vida nos convidam a ver o quanto a socialização da experiência em espaços (auto)biográficos podem reconfigurar todo processo de pesquisa e formação. São nesses momentos de busca do tempo perdido, como mostrou a rememoração proustiana, que o sujeito ao mesmo tempo em que narra sua história, torna-se a um só tempo pesquisador e auto(formador), assim como põe em movimento e 
(re)constrói dimensões humanas historicamente subsumidas à padronização da racionalidade.

\section{c-A (meta)reflexão da experiência narrativa}

Ao contrário do que se pode pensar, produzir narrativas autobiográficas e memoriais não se resume à doxa de cada sujeito, isto é, à opinião particular. Sem dúvida, o ponto de partida é a intimidade e seus mais complexos graus de subjetividade; no entanto, o processo formativo com narrativas autobiográficas pretende ir além. Sua pretensão é converter o senso comum e a opinião em algum gênero acadêmico, tal como o inexplorado e pouco valorizado memorial autobiográfico.

Desta forma, os cursistas-narradores foram chamados a exercitar uma habilidade pouco usual nos processos de formação continuada, a metarreflexão da experiência de formação acadêmica. Esse exercício foi permitido na medida em que a produção do memorial propôs a reflexão da trajetória formativa, o que é muito importante, mas que por si só não basta. É preciso dar um salto qualitativo no processo, provocando a reflexão sobre a reflexão exercitada, ou seja, a metarreflexão, podendo-se a partir dela, reinventariar o passado e dar sentido à experiência formativa, não apenas descrevendo-a, e sim interpretando-a. Isso porque a formação, a partir de narrativas, é uma experiência tridimensional em que se revolvem, imiscuem e condicionam, presente, passado e futuro no agora (ABRAHÃO, 2004).

Na reflexão do seu processo de vida e de formação, os sujeitos narradores puderam, construtivamente, compartilhar experiências e (re) significar seus processos formativos. Na medida em que os egressos teciam fios memoriais retrospectivos de sua formação, ressignificavam muitos de seus saberes e de suas práticas pedagógicas. Isso porque a atividade humana se dá num processo dialético de ação-reflexão-ação, constituindo neste movimento o universo da práxis, ou seja, uma atividade ontologicamente voltada para transformação de si mesmo e do mundo. 


\section{Considerações finais}

A raiz etimológica de narrador é o adjetivo latino gnarus, aquele que sabe. O seu contrário é ignarus [de onde provém a palavra ignorância], ou seja, aquele que não sabe ou desconhece. Nesta raiz, subsistem algumas daquelas qualidades do verdadeiro narrador que vimos em Benjamin: sua sabedoria ancestral, seu saber prático, sua capacidade de dar conselhos, seja ao vir de longe, em longas viagens pelos sete mares ou seja de perto, na longa viagem da vida, no caso do velho, com muita experiência para passar aos outros.

Deste ângulo, a pesquisa narrativa que apresentamos trouxe para a formação continuada de educadores os saberes e experiências de si próprias como protagonistas, que têm muito a dizer, porque assim como o marinheiro viajante ou o velho camponês experiente, percorreram um longo caminho de formação, rememorado no processo formativo pela produção dos seus memoriais autobiográficos de formação. Nessa produção foram instadas a exercitar suas experiências narrativas, socializá-las e, principalmente, refletir sobre a reflexão que fizeram de sua formação inicial, configurando-se como metarreflexão da experiência. Todo esse processo, conforme afirmam os autores citados neste artigo e que os relatos indicam, provocam ressignificações por parte do sujeito, que são novos modos de dar significado à própria vida, aos saberes e aos fazeres docentes. Daí a relevância da continuidade deste tipo de pesquisa, pois é preciso investigar mais de perto, em pesquisas futuras, como o processo formativo autobiográfico se converte em ressignificações identitárias. Neste trabalho, limitamo-nos a apresentar tão somente possibilidades.

$\mathrm{Na}$ pesquisa com narrativas autobiográficas, estamos diante da sabedoria de múltiplos narradores anônimos, cada um com sua porção de experiência a partilhar. E os pesquisadores narrativos são uma espécie de bardo contemporâneo, que coletam essas histórias, as ruminam, tornam suas [o alheio no meu alheio, de Bakhtin], e as transmitem a diversas comunidades de ouvintes. 
Pesquisadores narrativos amontoam linguagens, sobrecodificam e são atravessados pelas histórias que lhes são narradas. Mas se o caso é assim tão subjetivo e cheio de possíveis erros de paralaxes instrumentais e psicológicos, por quê ainda nos mantemos nesta empreitada indefinida? A resposta a esta questão não consiste em acertar ou errar, mas sim, dar vida narrativa às experiências de vida. Quem, senão, o narrador para fazer isso? Quem conheceria a grande guerra de Troia se não fosse Homero? Quem conheceria as pequenas aventuras de pesquisa-formação de L., M., A. se não as tivéssemos trazido neste trabalho?

Para encerrar, caberia aqui parafrasear o contador clássico brasileiro, Júlio Gouveia, que fechava os episódios telenovelísticos do Sítio do Pica-Pau Amarelo com um bordão mais ou menos assim: "Contei a minha história, mas essa já foi: entrou por uma porta e saiu pela outra, quem quiser que conte outra".

\section{Agradecimentos}

Os autores agradecem, respectivamente: ao Governo do Estado de Santa Catarina (UNIEDU/FUMDES - Programas de Bolsas Universitárias de Santa Catarina) pelo apoio mediante Bolsa de Doutorado; ao $\mathrm{CNPq}$ (Conselho Nacional de Desenvolvimento Científico e Tecnológico) pelo apoio financeiro mediante Bolsa Produtividade para esta Pesquisa.

\section{Referências}

ANDRADE, S. dos S. Juventude e processo de escolarização: uma abordagem cultural. Tese (Doutorado em Educação) — Faculdade de Educação, UFRS, Porto Alegre, 2008.

ANDREWS, M.; SQUIRE, C.; TAMBOUKOU, M. Doing narrative research. London: SAGE, 2008.

ABRAHÃO, M. H. M. (org.). A aventura (auto)biográfica: teoria \& empiria. Porto Alegre: EDPUCRS, 2004. PUCRS, 2004. 
ARFUCH, L. O espaço biográfico: dilemas da subjetividade contemporânea. Rio de Janeiro: EdUERJ, 2010.

ARFUCH, L. Memoria y autobiografia: explotaciones em los limites. 1. ed. Buenos Aires: Fondo de Cultura Económica, 2013.

BAKHTIN, M. Estética da criação verbal. São Paulo: Martins Fontes, 2003.

BENJAMIN, W. Magia e técnica, arte e política: ensaios sobre literatura e história da cultura. O Narrador. São Paulo: Brasiliense, 2012. (Obras Escolhidas v.1).

BENJAMIN, W. Origem do drama trágico alemão. Trad. João Barrento. 2.ed. Belo Horizonte: Autêntica, 2016.

BONDIA, J. L. Notas sobre narrativa e identidad (a modo de presentación). In: ABRAHÃO, M. H. M. (org.). A aventura (auto)biográfica: teoria \& empiria. Porto Alegre: EDPUCRS, 2004.

DANTAS, L. G. A opção da escola pelos pobres. Tese (Doutorado em Educação) PPGE em Educação, Faculdade de Educação, UNB, Brasília, 2014.

FERREIRA, M. M. História, tempo presente e história oral. Revista Topoi, Rio de Janeiro, v. 3, n. 5, p. 314-332, 2002.

GADAMER, H.-J. Verdade e método I. Trad. Flávio Paulo Meurer. 14. ed. Petrópolis: Vozes, 2014.

HARRISON, B. Life story research. London: SAGE Publications, 200

JOSSO, M.-C. Experiências de vida e formação. Natal: EDUFRN, 2010.

MEIHY, J. C. S. B. Os novos rumos da história oral: o caso brasileiro. Revista de História, São Paulo, v. 2, n. 155, p. 191-203, 2006.

NÓVOA, A. Apresentação. In: JOSSO, M.-C. Experiências de vida e formação. Natal: EDUFRN, 2010.

NÓVOA, A.; FINGER, M. (org.). O método (auto)biográfico e a formação. Lisboa: Ministério da Saúde, 1988. 
PASSEGGI, M. da C. Experiência em formação. Revista Educação, Porto Alegre, v. 34, n. 2, p. 147-156, maio/ago., 2011.

PROUST, M. Em busca do tempo perdido: no caminho de Swann-Combray. v. 1. Trad. Fernando Py. Versão Digital Source, 1913. Disponível em: <https:// projetophronesis.files.wordpress.com/2012/06/proust-em-busca-do-tempoperdido-1-no-caminho-de-swann.pdf >. Acesso em: abr. de 2017.

RICOEUR, P. Tempo e narrativa. São Paulo: WMF Martins Fontes, 2010.

SOUZA, E. C. de. (Auto)biografia, identidades e alteridade: modos de narração, escritas de si e práticas de formação na pós-graduação. Revista Fórum Identidades, Sergipe, v. 4, p. 37-50, jul./dez. 2008.

TORRIL, M. Reflections on the narrative research approach. In: HARRISON, B. Life story research. London: SAGE Publications, 2008.

Recebido: 24/01/2018

Received: 01/24/2018

Aprovado: 28/11/2018

Approved: 11/28/2018 